\title{
The Winding Road to Industrial Safety: Evidence on the Effects of Environmental Liability on Accident Prevention in Germany
}

\author{
Reimund Schwarze and Onno Hoffmeister \\ European Statistical Office (Eurostat), European Commission, 5 rue Alphonse Weicker, L-2721, Luxemburg. \\ E-mails: reimund.schwarze@ufz.de (Reimund Schwarze); onno.holffmeister@ec.europa.eu \\ (Onno Hoffmeister)
}

The German Environmental Liability Law (ELL) of 1991 has introduced far-reaching civil liability for environmental damages with the aim of increasing firms' efforts to prevent accidents. Previous studies find poor evidence that this goal has actually been achieved. One and a half decades after the introduction of that law, we undertake a new attempt to investigate the impact of the ELL on accident prevention. Our analysis is based on annual data on the number of environmental accidents per year, reported to the monitoring agency ZEMA, and the risk premium imposed by a large German insurer on environmental liability insurance (ELI). Examining the relationship between the ELI premium and accident prevention, we are able to model the dynamics of the adjustment process induced by the ELL. According to our results, the average number of environmental accidents per year has decreased from 35 before to 22 after the reform.

The Geneva Papers (2010) 35, 416-434. doi:10.1057/gpp.2010.16

Keywords: environmental liability; accident prevention; empirical analysis; Germany

\section{Introduction}

Environmental liability serves a dual objective in the economic theory, namely: preventing environmental damage and charging external costs - that is, costs previously borne by the injured party - to the polluter. The latter is also called the goal of internalisation. The preventive effect of environmental liability is evident in the number and range of measures taken to prevent accidents or in the changes of the frequency and/or severity of accidents. The internalisation effect of the law is evident in the number of successful court cases and the increase of the density of environmental liability insurance (ELI). The number of successful suits shows whether claims for damages can easily be won in court. But it tells us little about the preventive effect of liability. A low number of suits can be both an expression of disinclination to sue, and so regarded as failure of prevention, or as reflecting a reduction in damages. This question can only be clarified empirically through observation of accident data, and this procedure is followed below in this paper.

Numerous studies have previously looked into the prevention and internalisation effects of environmental liability law (ELL), mostly theoretically. The theoretical literature is generally concerned with transaction costs and the various legal barriers to 
successful environmental claims of private parties. With few exceptions, ${ }^{1}$ experts believe that environmental liability is largely ineffective and comparatively costly in reaching its goals. ${ }^{2}$ Empirical findings are also little in favour of environmental liability when it comes to its effects on internalisation and prevention. Ringleb and Wiggins, for example, find evidence on evasion from liability by means of undercapitalisation in the toxic substance transport and disposal in the United States In a complementary finding, Ulph and Valentini show that firms, with limited liability, evidently increased their bank borrowing by 15 to 20 per cent in the face of environmental liability. Alberini and Austin ${ }^{3}$ examine the preventive effect of environmental liability in a study commissioned by DG ENV of the European Commission. They look at annual changes in state-level emissions reported in the Toxics Release Inventory, relating them to the liability imposed on polluters by state laws, and state characteristics. Their main finding is that states liability policies toward environmental damages may exert some slight, additional pressure to reduce emissions of the most toxic industrial chemicals. The evidence of the effect of strict liability is suggestive but not strongly significant statistically (loc. cit., 26/7). In a later study (Alberini and Austin, 2002), ${ }^{3}$ the same authors examine how accidental releases of pollution into the environment (in the United States) was affected by the imposition of strict liability on the polluter, using variation across states in the liability provisions of Superfund laws in the period 1987-1995. They find that only after explicitly modelling the endogeneity of states' liability laws, strict liability is seen to reduce the seriousness of spills and releases. They also confirm the finding that under strict liability, firms may delegate risky production processes to smaller firms, which are partially sheltered from liability. Blancard and Laguna, ${ }^{4}$ in a recent paper, examine the stock market response to 76 petrochemical accidents to find that there is no stock market penalty for chemical substances releases if only ecological damages result. Previous studies on stock market responses to environmental accidents and toxic torts ${ }^{5}$ discover similar negligible, often only day of announcement effects on stock values with very few exceptions (Bhopal and Exxon Vadez). The latter can be explained by unprecedented, long-lasting lawsuits. Despite this generally discouraging evidence, the EU has, after a ten-year political debate, ${ }^{6}$ delivered benchmark European rules for environmental liability. The conceptual basis for this law-making was the so-called "Green Paper" of the EU Commission in 1993, which was followed by a "White Paper" in 2000 and, finally, enshrined into the 2004 EU directive on environmental liability (Council

\footnotetext{
${ }^{1}$ Katzman (1985) provides examples of safety enhancing effects of environmental liability in the chemical industry while Panther (1992) demonstrates in a rigorous economic model that "environmental liability is an almost ideal instrument to stimulate research and development in environmental safety" (ibid., p. 239).

${ }^{2}$ For an overview, see Dewees (1992).

3 Alberini and Austin (1999, 2000, 2002).

${ }^{4}$ Blancard and Laguna (2006).

${ }^{5}$ For example, Ananthanarayanan (1998); Bartsch (1998); Kuepper (1996); Muoghalu et al. (1990); White (1996), Lanoie and Laplante (1994).

${ }^{6}$ A comprehensive overview on this history of law-making is provided at http://ec.europa.eu/environment/ liability/index.htm.
} 
418

Directive, 2004). ${ }^{7}$ This directive passed the European legislation in 2005 and was implemented into national law in 2007.

Considerable experience with environmental liability has been developed in Germany where an early first move towards strict liability was made in 1990. This paper examines whether the German ELL, which proceeded the EU law-making, has been successful in reaching its economic objectives, that is, whether it led to an internalisation of environmental damage and increased standards of accident prevention. It reviews the specifics of this legislation and the results that surfaced from it. It is divided into two sections. The next section surveys previous studies that look into the immediate effects of the German ELL. Since these studies are entirely studying the short-term effects of the German ELL, we undertake an effort in the subsequent section to study the effects in a longer period (15 years) based on new data available from the insurance industry and the federal environment agency of Germany. The final section concludes.

\section{The German ELL and its immediate effects}

Germany has a multi-tiered system of environmental liability. Regulation on environmental liability can be found under general civil law ( $\$ 823$ of the Civil Code), in the Law on Neighbourhoods ( $\S 906,1004$ of the Civil Code) as well as various environmental legislations, for example, the Federal Water Act (\$ 22) and the Federal Soil Conservation Act ( $\$ 24)$. The ELL stands out as it is the only legislation that is expressedly and primarily geared to preventing environmental damages and to internalising social cost. The justification by the legislature on the ELL states that the legislation is intended "to bring lasting improvement to the legal position of the injured party, inducing those who cause damage to the environment to take efforts". Moreover, it shall "impose cost on environmentally damaging production processes, help making the products and services involved more expensive on the market". It should also "aid to implement measures to avoid damage where they are most cost-effective". 8

The key rule in the law is a strict liability for environmental risk, although it is limited to specifically named installations and their operation. ${ }^{9}$ Its effect is strengthened by a presumption of causality, making it easier for the plaintiff to bring evidence. ${ }^{10}$ The presumption of causality can only be refuted by the defendant with specific arguments

${ }^{7}$ Council Directive (2004a)

${ }^{8}$ Draft environmental liability law of 1990, Bundestagsdrucksache 11/7104-Begründung zu A, Allgemeiner Teil (Justification on A, General Section).

${ }^{9}$ The law states: "If a person is killed, if he suffers physical injury or impairment to his health, or if an item is damaged through an environmental effect caused by one of the plants listed in Annex A the owner of the plant is obliged to compensate the injured party for the injury or damage thus caused" (§ 1 ELL).

${ }^{10}$ The law states: "If a plant could be deemed in the circumstances of the individual case to have caused the damage in question it is presumed that the damage has been caused by that plant. Whether a plant may be so deemed will depend in any individual case on its operation, the facilities used, the type and concentration of the substances used and released, the meteorological conditions, the time and place of the damage incurred, the nature of the damage and all the other factors that indicate the cause of the damage in any individual case" (§ 6, Para. 1 ELL). 
that are precisely defined by law. Chief among them are maintaining "normal operation", that is, operation without disruption. ${ }^{11}$ The injured party's position is also improved in that the ELL requires the plant operator and the environmental authorities to give the plaintiff information to establish his claim. In addition, a mandatory insurance (that de jure could be substituted by a bank guarantee ${ }^{12}$ ) for plant operators ensures that claims for damages can be met. Prima facie, therefore, the ELL would appear to be a stringent and appropriate set of regulations that will achieve its objectives.

A look at the jurisdiction in the last 15 years disappoints this expectation, however. Since the ELL was passed, altogether only six court decisions have been given on the basis of this legislation. Only one was for the plaintiff, while five were for the defendant. The response to this jurisdiction in the legal literature is divided. Some commentators see it as progress, while others complain of stagnation or even regression. ${ }^{13}$ In essence, legal practice has not changed in 15 years, for environmental cases were also rare before the ELL came into force, and few were successful.

By contrast, insurance practice has changed considerably. This applies both to the policy structure and the density of insurance. Whereas in the 1970s the environmental risk was not specified and sometimes just added on to the general third-party insurance as a free "extra", we now find, in the ELI model offered by industrial insurers since $1993,{ }^{14}$ a differentiated system of insurance for individual plants with strict regulations to prevent the misuse of insurance, and with appropriate amounts to be paid by the claimant (e.g., for damage to his own property). The contract is only signed when a safety audit has been carried out and risk consultations have been given on the spot. ${ }^{15}$ Many German industrial insurers have set up their own or independent risk consultancy firms, and developed computerised risk analysis models to be used on the spot, even in small and medium-sized firms. ${ }^{15}$ The readiness of companies to take out ELI is high, although there has not been a wave of lawsuits. By 2003, insurance policies had been taken out for around 130,000 installations. ${ }^{16}$ Insurance is compulsory only for less than 1 per cent of these, in other words almost all the insurance is voluntary. This raises the question how a law, that imposes only a low liability risk on

${ }^{11} \S 6$, Para. 2 ELL states: "Para. 1 does not apply if the plant has been operated in accordance with its design and purpose and if no disruption to its operation has occurred".

${ }^{12}$ Bank guarantees were de facto never used in practice as a substitute for the mandatory insurance stipulated in $\$ 19$ ELL.

${ }^{13}$ Salje (2000) concludes that "the efforts of the Federal Environment Ministry to extend the concept of liability for hazard on the ground and in the air have not borne fruit", while Wagner (1998) sees the one successful case as a "valuable guideline in the process of environmental liability", but Gottwald (1992) believes that the ELL has given plaintiffs "stones not bread".

14 The implementation of the regulation on mandatory ELI started with the so-called "ELI model" developed by the German Insurance Association (GDV) in 1993.

15 Vogel (1995).

${ }^{16}$ A total of 104,915 insurance contracts have been reported to the German Insurance Association in 2003. Based on the market shares of the non-reporting firms it can be set at 128,070 contracts in that year. The number of installations must not be confused with the number of plants. Most plants, for example, in the chemical industry, compass a large number of installations and, thus, carry several insurance contracts for that purpose. 
companies, could give rise to such a comprehensive demand for insurance. One possible explanation is that companies are not at all sure of the exact legal implications or the practical consequences of the ELL. This uncertainty is increased by the fact that the ELL is embedded in a dynamic liability and insurance policy context; for example, it is backed up by numerous new regulations on firm owner and product liability. For example, the Law on Control and Transparency (KonTraG) of 1998 introduced a directors' liability for a breach of the duty to establish an organisational "early warning system" to detect business risk, including environmental liabilities, at the earliest possible stage.

In the immediacy of the ELL, several empirical analyses of its preventive effects were undertaken. Feess-Dörr et al. ${ }^{17}$ examined companies' strategies to cope with environmental liability risks before the introduction of the new law and changes in view of the introduction of environmental liability. They used structured interviews in ten large chemical industry plants between November 1988 and January 1989. Their most important results are:

1. The companies questioned were not planning any fundamental changes to their risk provision for their plants, production and products. Nor would their present efforts in this field be intensified in view of the coming legislation, as they regarded their present safety level as already very high.

2. Companies varied in their estimate of the need for additional risk provision. Although big companies pointed to their functioning safety management, some smaller and midsize firms still saw considerable shortcomings here. But in the view of the firms themselves this was chiefly a result of shortcomings in implementing the existing legal requirements.

3. Companies expected the more stringent liability requirements to involve growing expenditure to deal with environmental litigation with a rise in claims for damages. As a result, the ELL was only expected to bring changes in damage regulation but not in damage prevention.

Several studies undertaken for the European Commission have examined the economic effects of environmental liability. ${ }^{18}$ In the study on Germany, ${ }^{19}$ a survey was carried out of the investment behaviour of firms in the iron, sheet metal and metals processing industry in view of the new ELL. The most important result is that, with the high level of investment already reached, the ELL did not give rise to any additional voluntary environmental protection investment. ${ }^{20}$

Herbst $^{21}$ examined the stimulus to companies' risk policy from the ELL. This study is based on surveys of industrial firms and associations from 1992 to 1993. It showed that only a few companies were expecting the changes in the liability norms to lead to changes in production or an improvement in corporate risk policy. This scepticism was

\footnotetext{
${ }^{17}$ Feess-Dörr et al. (1992).

${ }^{18}$ See http://ec.europa.eu/environment/liability/background.htm.

19 Kuepper (1996).

${ }^{20}$ Voluntary environmental protection investment in this study is investment "not enforced by the legislature (emission protection, industrial supervision etc.)".

${ }^{21}$ Herbst (1996).
} 
based on the widespread separation of liability and safety technology in companies' organisation, and on the fact that the legislation on environmental liability only covers a small part of environmental damage (less than 1 per cent of the average pollution costs). ${ }^{22}$

Bartsch $^{23}$ analysed the movements in share prices after three major events connected with the ELL. They were the Sandoz accident of 1986, the announcement of more stringent environmental liability in Germany in 1989 and the passing of the ELL in 1990. The author examined the share prices of selected firms in the chemical industry that might be assumed to be particularly strongly affected by more stringent environmental liability requirements. The two most important results of the study are:

1. The prices of the shares of the companies affected did not show any significant deviation from the normal trend close in time to the events named.

2. The investment risk in buying chemical industry shares did not change significantly close in time to these events.

Schwarze $^{24}$ measured the preventive effect of the ELL on the basis of the trend in damages claims and accidents in ELI and the trend in accidents reported to the Central Registration Office for Breakdowns and Accidents in Industrial Installations (ZEMA) at the Federal Environment Agency (FEA). This study showed that the likelihood of accidents fell from 1993 to 1997, while at the same time take up of the new ELI accelerated. However, this result faced critique because of the very short time period on which it is based. Table 1 gives a survey of these early results.

\section{The effects of the German ELL after 15 years}

In this section, we look at the effects of the German ELL based on a longer period (15 years) and new data available from the insurance industry and the FEA. The insurance data is of a leading German industrial insurer. It gives the annual premium turnover in the branch of ELI based on the new environmental insurance policy (described above). The market turnover of this policy has been estimated on the basis of the market share of this insurer. The new ELI was introduced in 1993 by the German Insurance Association and consequently adopted by all national and foreign insurers in the German market. It can be seen as the institutional transmitter of the ELL into the "world of insurance and business". The series of insurance premiums covers a time period of 15 years (1988-2002), five years of which report the premium income of the pre-existing policy (1988-1992), while ten years are based on the sale of the new ELI (1993-2002). The ZEMA statistics of the FEA reports, from 1991 on, the number of accidents with release of dangerous substances into the plant's environment as defined in Annex VI, Part 1, of the German Breakdowns Ordinance (Stoerfallverordnung). Accidents of this sort are rare in Germany (about ten per year on average) but they are

\footnotetext{
${ }^{22}$ The share is actually less than 1 per cent of total environmental protection costs, which in turn only account for a small part of a company's total costs (less than 5 per cent).

${ }^{23}$ Bartsch (1998).

${ }^{24}$ Schwarze (1998, 2001).
} 


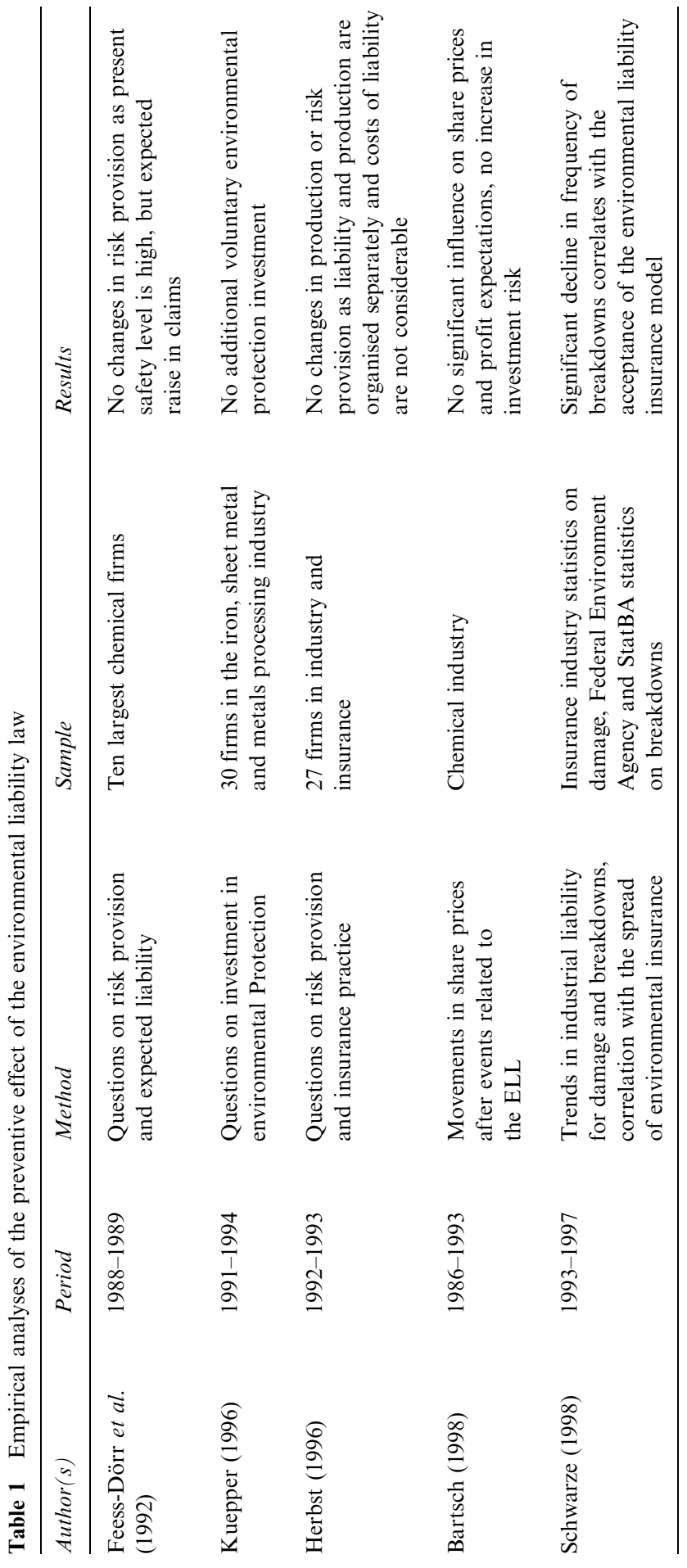




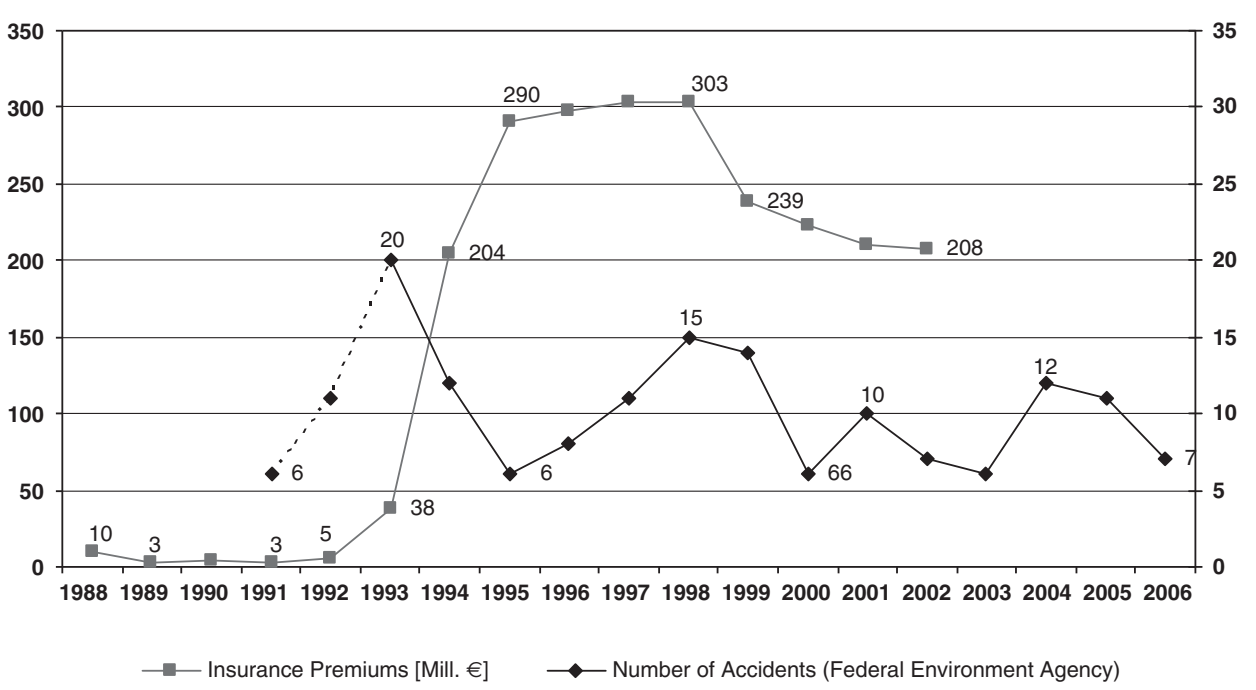

Figure 1. Insurance premiums and number of accidents (1988-2006).

reliable as a source of data because of the fact that they are backed by publicly available single accident reports in the internet (http://www.umweltbundesamt.de/zema/ download.html).

Figure 1 depicts both time-series. The development of insurance premiums shows a strong path-dependency. The huge rise immediately after the introduction of the ELI from 1993 to 1995 seemingly led to an overshooting and subsequent readjustment in the second half of the 1990s. After a maximum was reached in 1997, the amount of the premium lowered, probably because the insurees corrected their demand in the light of the unchanged number of successful court suits, or because emerging competition on the market for ELI forced the insurers' to lower their mark-ups on market prices. ${ }^{25}$ In the analysis below we provide evidence for a third type of explanation: that the fall in the premium was a response to growing accident prevention undertaken by firms. The time series of accidents shows an initial strong increase of reported events in the set-up and enforcement period of this new reporting duty in 1991 and 1992. The ZEMA supposes that it is purely the result of the initial improvement of the survey methods (2006, p. 7). From 1993 on, the number of reported events follows an oscillating path with diminishing amplitude. A slightly downwards sloping trend can be observed. However, part of this trend might be the result of a major change of reporting rules, which occurred in 2000, following the implementation in Germany of the

\footnotetext{
${ }^{25}$ Indeed, in 1999 a giant U.S. industry insurer (AIG) introduced a new, more costumer-orientated policy (covering seld-sustained damages to soils) into this so far self-regulated, German insurer dominated line of insurance. This so-called "Bodenkasko" was then quickly adopted and even extended by several German insurers. See Ruetz (2001) for the full story.
} 
SEVESO II-directive of the European Union (Council Directive, 1996), ${ }^{26}$ the effect of which was an immediate decrease in the number of reported events. ${ }^{27}$

To summarise, we see indeed a strong increase in premium turnover following the introduction of new liability rules into the "world of insurance and business". An effect of the reform on the number of accidents, however, is difficult to observe on first sight. In the following, we will improve our understanding of the distortions in the data and the processes driving the firms' efforts for accident prevention and find strong evidence for such effect on the basis of econometric techniques.

\section{An economic model of accident prevention}

For modelling the impact of the ELL on accident prevention, we introduce a cost function which depicts the relationship between the cost of accident prevention and the number of environmental accidents $(A)$. We assume that the cost of prevention increases in prevention efforts; it thus decreases in the number of accidents. Furthermore, we assume that the cost of avoiding an additional accident becomes greater, the safer the industrial facility already is. Accordingly, prevention costs can be thought of as a decreasing and convex function of environmental accidents, such as

$$
C(A)=\alpha A^{\beta} \text { with } \alpha>0 \text { and } \beta<0 .^{28}
$$

Cost incurs for a company not only from prevention efforts but also from the obligation to compensate for environmental damage in case of an accident. The amount of this liability $(L)$ should be dependent, besides the number of caused accidents, on the legal framework. We describe this relationship by the cost function

$$
L=\gamma \mathrm{e}^{\delta R+\varepsilon A} \text { with } \delta>0 \text { and } \varepsilon>0 .
$$

$R$ is a binomial variable which is 0 in the one legal regime, and 1 in the other. $\delta$ signifies the strictness of the legal framework. More specifically, $\left(\mathrm{e}^{\delta}-1\right)$ is the rate by which, at a given number of accidents, the firms' liability is greater in regime 1 than in regime 0 . $\varepsilon$ is the elasticity with which liability reacts to the number of accidents.

As firms seek to minimise total costs, $(C+L)$, they choose an equilibrium level of prevention, associated with the tolerated number of accidents $A^{*}$, at which the

\footnotetext{
${ }^{26}$ Council Directive (2004b)

${ }^{27}$ There is a good reason to expect the number of accidents reported to decrease as a result of the new reporting rules as the reporting unit has been changed to the higher, more aggregated level of sector of production ("Betriebsbereich") compared to the previous reporting of installations ("Anlagen"). A sector of production usually contains a large set of installations. However, the change in accidents reported after 2000 can also be because of other reasons.

${ }^{28}$ We chose a generalised functional form to simplify our theoretical exposition in this paper and to allow for a smooth econometric approach. This is conducted in a way to avoid any loss of generality of the results.
} 
marginal gain from cutting prevention cost exactly outweighs the marginal expected liability:

$$
\begin{aligned}
& \min _{X}(C+L) \Leftrightarrow \frac{\partial C(A)}{\partial A}+\frac{\partial L(R, A)}{\partial A} \\
& =0 \Leftrightarrow(\beta-1) \log A^{*}-\varepsilon A^{*}=\log \left(-\frac{\gamma \varepsilon}{\alpha \beta}\right)+\delta R .
\end{aligned}
$$

We assume that firms lack the informational capacities for assessing the true expected loss resulting from potential environmental accidents. This risk assessment is the primary competence of insurance companies. They translate the expected cost arising from being held liable for environmental damages into insurance premiums which they deduct from insurees. Hence, from the firm's perspective, the prevention level that leads to $A^{*}$ accidents is not directly dependent on $R$, but transmitted by the premium, $L$, reflecting the expected liability in a given legal environment for a given expected number of accidents. In the equilibrium, insurers impose the premium $L^{*}=L\left(R, A^{*}\right)$ and firms set their equilibrium level of prevention on the basis of that premium: $A^{*}=A^{*}\left(L^{*}\right)=A^{*}\left(L\left(R, A^{*}\right)\right)$. In the short run, however, the premium is determined on the basis of the currently observed prevention level and firms decide upon their prevention activities on the basis of the premium currently imposed. We define the premium set in the short run as $L_{S}=L\left(R, A_{S}\right)$, where $A_{S}$ is exogenous to the insurers. The short-run prevention level is $A_{S}=A^{*}\left(L_{S}\right)$, where $L_{S}$ is exogenous to the firm. We obtain this latter function by using Eq. (2) and putting it into Eq. (3).

$$
A_{S}=A^{*}\left(L_{S}\right)=\left(-\frac{\varepsilon}{\alpha \beta}\right)^{1 /(\beta-1)} L_{S}^{1 /(\beta-1)} .
$$

Differentiating over $L_{S}$, we obtain the short-run change in prevention:

$$
d A_{S}=\left(-\frac{\varepsilon}{\alpha \beta}\right)^{1 /(\beta-1)} \frac{1}{\beta-1} L_{S}^{(2-\beta) /(\beta-1)} d L^{S} .
$$

The short-run change in the premium is given by the total differential of Eq. (2) over $R$ and $A_{S}$ :

$$
\begin{aligned}
d L_{S} & =\frac{\partial L_{S}\left(R, A_{S}\right)}{\partial R} d R+\frac{\partial L_{S}\left(R, A_{S}\right)}{\partial A_{S}} d A_{S} \\
& =\gamma \delta e^{\varepsilon A_{S}} e^{\delta R} d R+\gamma e^{\delta R} \varepsilon e^{\varepsilon A_{S}} d A_{S} .
\end{aligned}
$$

As we see from Eq. (6), the overall change in the insurance premium, reflecting expected liability, can be decomposed into a legal and a preventive effect. The legal effect is represented by the first summand and measures the change in expected 


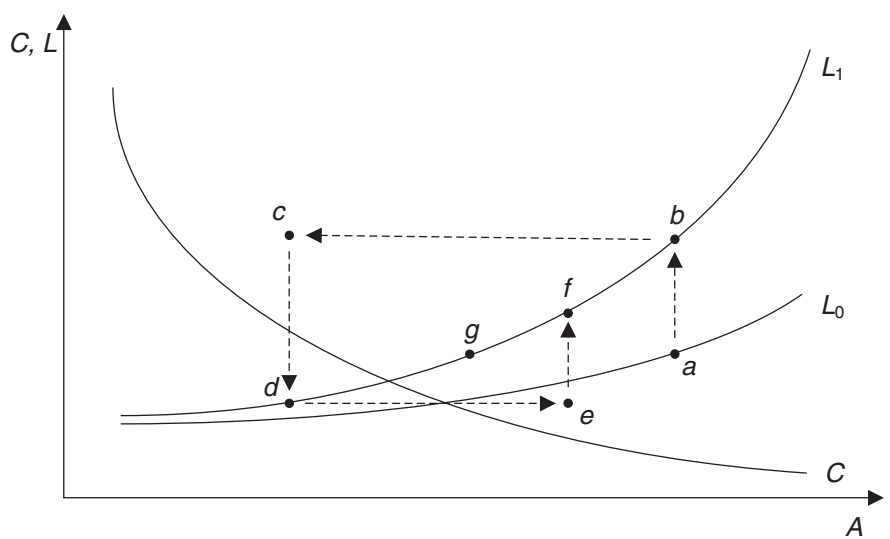

Figure 2. Adjustment of insurance premiums and prevention efforts.

liability under the condition that the prevention level remains constant. The prevention effect is represented by the second summand and measures the change in expected liability purely caused by changes in the firms' prevention levels.

The Eqs. (5) and (6) reveal the reciprocal nature of the adjustment process. Companies adjust their prevention levels to changes in the premium levels while insurance companies consequently take this adjustment into account in the determination of the premiums. From this follows a dynamics which is caused by a sequence of changes:

- In the first stage, as an immediate consequence of the ELL reform, the expected liability and the degree to which liability can be avoided by means of prevention increases for each prevented accident. Accordingly, the liability curve in Figure 2 shifts from $L_{0}$ to $L_{1}$. As a consequence, insurers impose a higher premium, even though the prevention level remains the same. The arrow $a b$ represents this direct legal effect.

- In the second stage, companies realise that they can save costs by extending their accident prevention, because the expenses for additional prevention efforts will be overcompensated by the reduction of the expected loss in case of an accident, as signalled by the premium they pay. ${ }^{29}$ Accordingly, the number of prevented accidents will rise until the marginal cost of accident prevention equals the marginal expected liability which firms observed in point $b$. This behavioural adjustment is represented by the arrow $b c$.

- In the third stage, insurance companies, under the pressure of competition, notice that they can reduce their premiums - and thereby achieve an advantage to their

${ }^{29}$ Throughout this paper we assume that premiums are fair, that is, reflecting expected damages. There are no loadings except for temporary rents that result from a lagged adjustment of premiums to the reduction in the number of industrial accidents (explained below). 
competitors - because expected liability has lowered as a result of the increase in prevention. Accordingly, the premium level falls from point $c$ to point $d$.

After the third stage, the marginal liability is in point $d$ smaller than in point $b$. Companies had based their optimisation of prevention on the marginal liability observed in point $b$. Therefore, in point $d$ they have an incentive to be less cautious. As a consequence, the stages 2 and 3 will be repeated, this time leading to a reduction of prevention efforts and a growth of insurance premiums, as demonstrated by the arrows de and ef. After several repetitions, a new equilibrium will be approached, marked by point $g$, in which the marginal expected liability equals the negative marginal cost of prevention, and the insurance premium accurately reflects the expected loss to be covered in case of an accident.

\section{Data}

We measure the expected liability, $L$, arising from environmental accidents in Germany in terms of the total of insurance premiums firms paid each year for the ELI police offered by a leading German industry insurer (see Figure 1). ${ }^{30}$ This time series has one unit root, as is confirmed by the Dickey-Fuller ( $p$-value: 0.163 ) and PhillipsPerron tests ( $p$-value: 0.736$).{ }^{31}$ Its first difference is autoregressive of order one. The autoregression coefficient, in the following $\rho$, amounts to 0.44 and, according to the $t$-test, is significant on the 10 per cent-level. This leads us assuming the following data generation process:

$$
\Delta \log L_{t}=\rho \Delta \log L_{t-1}+u_{t} \Leftrightarrow \log L_{t}=\log L_{t-1}+\rho\left(\log L_{t-1}-\log L_{t-2}\right)+u_{t},
$$

where $u_{t}$ is distributed with zero mean and constant variance. No serial correlation has been found in $u_{t}$. The process described by Eq. (7) is typically caused by adaptive expectations, as they often occur, for example, in stockkeeping or investment decisions. ${ }^{32}$ Insurance companies do not immediately adjust their premiums from one period to the next. Instead, in period $t-1$, the premium level of the next period, $L_{t}$, is chosen by taking into account the change in the period before, which is ( $\log L_{t-1}-\log$ $\left.L_{t-2}\right) . u_{t}$ represents the "innovation", for example, the component of the premium which is independent from the development in the past.

We measure $A$ by the number of accidents reported to the monitoring agency ZEMA. This time series is free from auto-correlation both in levels and differences.

\footnotetext{
${ }^{30}$ We thereby abstract from possible effects on the aggregate insurance premium which could eventually result from the change of the size of the sector of firms facing a positive risk of being assumed liable for environmental damage. An increase (a decrease) in the total of insurance premiums can be interpreted as either higher (lower) prices for any given contract or an increase (decrease) of the rate of coverage, for example, extended or new sold insurance policies, in the sector. In both cases, the average premium to be paid by a firm in that sector rises (falls).

${ }^{31}$ Of course, the size of these $p$-values should be interpreted with care, as these tests are based on only 15 observations. However, the shape of the curve in Figure 1 strongly supports our belief that the time series of the insurance premium is integrated of order one.

32 Metzler (1941).
} 
$R$ is coded as 1 from 1993 onwards and 0 in the years before. As noted above, the year 1993 can be regarded as the point in time where the new liability regime (of 1990) was translated into "the world of insurance and business".

\section{Econometric specification}

Eq. (2) expresses the dependence of the insurance premium on the legal rules and prevention levels. Using the logarithmic form,

$$
\log L=\log \gamma+\delta R+\varepsilon A,
$$

and taking into account the nature of the data generation process, as described in Eq. (7), we estimate Eq. (8) in first difference and include the lagged values of $\Delta \log L_{t}$ :

$$
\Delta \log L_{t}=\delta \Delta R_{t}+\varepsilon \Delta A_{t-1}+\rho \Delta \log L_{t-1}+u_{t}
$$

We thereby assume the premium level to react to changes in the number of accidents that occurred in the year before.

The impact of changes in insurance premiums on the firms' efforts for accident prevention is described by Eq. (4). Expressed in logarithms, this equation is

$$
\log A=\frac{1}{\beta-1} \log \left(-\frac{\varepsilon}{\alpha \beta}\right)+\frac{1}{\beta-1} \log L .
$$

To take into account a structural shift in the time series of accidents in 2000 , possibly resulting from the change of reporting rules, we generate a jump variable, $B_{t}^{00}$, which is 1 from the year 2000 onwards and 0 in the years before. We estimate Eq. (10) in first difference, in order to cope with the non-stationarity of the logarithmic premium levels also in that regression, ${ }^{33}$ and we assume that firms adjust their prevention to premiums with a time lag of one year. The resulting econometric model is given by

$$
\Delta \log A_{t}=\frac{1}{\beta-1} \Delta \log L_{t-1}+\varsigma \Delta B_{t}^{00}+v_{t}
$$

The coefficient $\delta$ in Eq. (9) represents the change taking place in the first stage of the adjustment process described above, caused purely by the modification of the legal framework. $1 /(\beta-1)$ in Eq. (11) represents the effect of the second stage, in which firms adjust their prevention efforts to the change of the premiums. Finally, $\varepsilon$ in Eq. (9) is associated with the third stage and measures the degree to which insurers readjust their

\footnotetext{
${ }^{33}$ Initially, we also included a one-period lag of $\Delta \log L_{t-1}$ as an independent variable. Its coefficient turned out to be insignificant ( $p$-value: 0.829).
} 
premiums to the changed prevention levels under the condition of an unchanged legal environment.

\section{Results}

For the estimation of the legal effect on the premium level, $\delta$, we can use all observations in $\Delta \log L$ from 1990 to 2002 . By contrast, the observations available for the estimation of $\varepsilon$ are limited to the shorter time span, from 1994 to 2002, during which the time series of $\Delta \log L$ and $\Delta A$ overlap. So as to not lose information on the former effect, we estimate the coefficients $\delta, \varepsilon$ and $\rho$ in Eq. (9) with two separate regressions: one, from which the term $\delta \Delta \log A_{t-1}$ is excluded and which uses all observations from 1990 to 2002, and another, which is confined to the nine observations from 1994 to 2002 and in which $\delta \Delta R_{t}$ is thus zero. ${ }^{34}$ Both equations are estimated simultaneously together with Eq. (11) in the scope of a SURE system, thereby taking into account that the residuals should be correlated across equations. ${ }^{35}$

The results of the regressions are presented in Table 2. They reveal that 1 per cent growth of the ELI premium leads, on average, to the prevention of 0.33 per cent of the environmental accidents. In turn, each avoided accident makes the growth rate of the insurance premium fall by three percentage points. The immediate legal effect on the logarithmic premium, at given prevention level, is estimated to be 1.83 . This implies an increase of the insurance premium by $5.23\left(\mathrm{e}^{1.83}-1\right)$ times as an immediate response to the enforcement of the ELL in 1993. Except for $\varepsilon$, all point estimators turned out significant at the 1 per cent level, and also for $\varepsilon$ the $p$-value is with 0.012 only slightly above that limit. The model explains more than four-fifth of the variance in the annual growth rate of insurance premiums observed from 1994 to 2002 and almost 60 per cent of the annual growth rate of accidents during that time. Despite this remarkable fit, because of the limited number of observations, the regression results should not be taken as a firm statistical proof of the relationships derived in the economic model above. Nonetheless, it considerably improves our understanding of the processes observable in the ten years following the introduction of the ELL.

The estimator for $\beta$ is $-2.003(1-1 / 0.333)$. This means, reducing the number of accidents by a half requires quadrupling the prevention cost (see Eq. 2). The coefficient $\varepsilon$ is estimated as 0.031 , implying that with each additional accident the growth rate of the insurance premium goes up by 3.1 percentage points (see Eq. 3). Finally, the estimated value of 1.83 for $\delta$ means that the ELL reform had the immediate effect to push up the insurance premium to be paid per environmental accident by around 5 and a quarter $\left(\mathrm{e}^{1.83}-1\right)$ times, heralding the adjustment process described in Figure 2.

${ }^{34}$ The exclusion of $\varepsilon \Delta \log A_{t-1}$ does not have any impact on the coefficients $\delta$ and $\rho$ if $\Delta \log A_{t-1}$ is noncorrelated to $\Delta R_{t}$ and $\Delta \log L_{t-1}$. A significant effect of the anticipated reform is unlikely, as firms lack the informational capacities to assess the impact of the reform on expected environmental liability. At the 10 per cent significance level, no correlation between $\Delta A_{t-1}$ and $\Delta \log L_{t-1}$ has been found in the data (correlation coefficient: 0.12 , p-value: 0.742 ).

35 The estimators of $\rho$ in the two equations based on Eq. (9) have been restricted to be equal. This equality has not been refuted by the Wald test on the 10 per cent level. 
Table 2 Regression results

\begin{tabular}{|c|c|c|c|}
\hline \multirow[t]{2}{*}{ Dep. var. } & \multirow{2}{*}{$\frac{\text { Equation } 1}{\Delta \log L_{t}}$} & \multirow{2}{*}{$\frac{\text { Equation } 2}{\Delta \log A_{t}}$} & \multirow{2}{*}{$\frac{\text { Equation } 3}{\Delta \log L_{t}}$} \\
\hline & & & \\
\hline$\Delta R_{t}$ & $1.829 * * *$ & - & $1.829 * * *$ \\
\hline$\Delta A_{t-1}$ & - & - & $0.031 * *$ \\
\hline$\Delta \log L_{t-1}$ & $0.471 * * *$ & $-0.333 * * *$ & $0.471 * * *$ \\
\hline$\Delta B_{t}^{00}$ & - & $-0.959 * * *$ & - \\
\hline$R^{2}$ & 0.619 & 0.590 & 0.834 \\
\hline Obs. & 13 & 10 & 9 \\
\hline Period & 1990-2002 & 1994-2003 & 1994-2002 \\
\hline
\end{tabular}

$* * * / * * / *$ : significant at the 1-/ 5-/ 10-per cent level.

As noted above, our model is grounded on the assumption that the ELL reform did not have any direct effect on accident prevention, for example, a prevention effect not transmitted by the ELI premium. For the verification of this hypothesis, we introduce a coefficient, $\kappa$, into Eq. (11), which measures an eventual effect of the reform on the yearly number of accidents with a time lag of one year:

$$
\Delta \log A_{t}=\kappa \Delta R_{t-1}+\frac{1}{\beta-1} \Delta \log L_{t-1}+\varsigma \Delta B_{t}^{00}+v_{t}
$$

A $t$-test on $\kappa$ leads to a $p$-value of 0.87 . It thus does not reject our hypothesis that firms were reluctant to increase their efforts to prevent accidents as a direct response to the reform.

\section{Simulation of the change}

A simulation based on the coefficients in Table 2 illustrates the course of the adjustment process after the ELL reform, free from the distortions in the data, as predicted by the model. Using Eq. (9) we can calculate the change in the premium level and the number of accidents in the $t^{\text {th }}$ year on the basis of their changes in the year before, while taking into account the change in the legal environment:

$$
\Delta \log \hat{L}_{t}=\delta \Delta R_{t}+\varepsilon \Delta \hat{A}_{t-1}+\rho \Delta \log \hat{L}_{t-1},
$$

where

$$
\Delta \log \hat{A}_{t}=\frac{1}{\beta-1} \Delta \log \hat{L}_{t-1} \Leftrightarrow \Delta \hat{A}_{t}=\left(\frac{1}{\beta-1} \Delta \log L_{t-1}-1\right) \hat{A}_{t-1}
$$

with $t=1,2, \ldots, 10$ and $\Delta \log L_{0}=0$ and $\Delta A_{0}=0 . \hat{A}_{t}$ is measured according to the reporting standards applied before 2000 . The predicted change in premiums in the year 
$t$ can be traced back to the changes observable in the year $t-\tau$, the year of the effective implementation of the ELL (1993). From Eq. (13) follows

$$
\Delta \log \hat{L}_{t}=\sum_{k=0}^{\tau} \rho^{k} \delta \Delta R_{t-k}+\sum_{k=0}^{\tau} \rho^{k} \varepsilon \Delta \hat{A}_{t-k-1}+\rho^{\tau+1} \Delta \log \hat{L}_{t-\tau} .
$$

Eq. (15) additively decomposes the predicted growth in premium levels into three effects: The first summand represents the repercussion of the reform-impulse, the second summand the cumulated influence of past changes in the number of accidents, and the third summand the impact of the initial level of premium growth which was observable in the year before the reform. As the impact multiplier $\rho$ is smaller than one (compare Table 2), the influence of changes in the independent variables on the premium level geometrically diminishes as time goes by. After five years, only 2.3 per cent $\left(0.47^{5}\right)$ of the initial reform impulse are reflected in the current premium growth. After seven years, its impact has already diminished to 0.5 per cent of the amount in the reform year.

Table 3 shows the predicted development of premium levels and yearly number of accidents from 1993 to 2002, decomposed into the resonating reform impulse (forth column) and the cumulated effects of past changes in the yearly number of accidents (fifth column). In this simulation, the initial premium growth has been set to zero, thus $\Delta \log \hat{L}_{t-\tau}=0$, as we aim to predict the developments to be expected independently from that growth rate. We set $A_{0}=20$, which is the earliest value of the yearly accidents reported by the ZEMA with sufficient reliability. The table shows a rapid growth of the premium (ninth column) in the first years after the reform. This levels off in the following time and turns into negative after 1996. The number of accidents declines from 1994 onwards (sixth column). Their absolute yearly changes steadily diminish, and after 1998 the number of accidents even modestly goes up again.

The decomposition reveals that the dampening and reversal of the premium growth from 1993 to 1997 is attributable to both the diminishing impact of the reform impulse and the fall in the number of accidents. This fall, in turn, is explained by increased

Table 3 Predicted development of accidents and insurance premiums in response to the ELL

\begin{tabular}{rccccccrc}
\hline$t$ & Year & $\Delta R$ & $\Sigma_{k} \rho^{k} \delta \Delta R_{t-k}$ & $\Sigma_{k} \rho^{k} \varepsilon \Delta A_{t-k-1}$ & $\Delta A_{t}$ & $\Delta \log L_{t}$ & $\Delta A / A[\%]$ & $\Delta L / L[\%]$ \\
\hline 1 & 1993 & 1 & 1.8295 & 0.0000 & 0.00 & 1.8295 & 0.00 & 523.05 \\
2 & 1994 & 0 & 0.8615 & 0.0000 & -9.12 & 0.8615 & -45.61 & 136.67 \\
3 & 1995 & 0 & 0.4057 & -0.2849 & -2.71 & 0.1208 & -24.93 & 12.84 \\
4 & 1996 & 0 & 0.1910 & -0.2188 & -0.32 & -0.0278 & -3.94 & -2.74 \\
5 & 1997 & 0 & 0.0900 & -0.1131 & 0.07 & -0.0231 & 0.93 & -2.29 \\
6 & 1998 & 0 & 0.0424 & -0.0510 & 0.06 & -0.0086 & 0.77 & -0.86 \\
7 & 1999 & 0 & 0.0199 & -0.0221 & 0.02 & -0.0021 & 0.29 & -0.21 \\
8 & 2000 & 0 & 0.0094 & -0.0097 & 0.01 & -0.0003 & 0.07 & -0.03 \\
9 & 2001 & 0 & 0.0044 & -0.0045 & 0.00 & -0.0001 & 0.01 & -0.01 \\
10 & 2002 & 0 & 0.0021 & -0.0021 & 0.00 & -0.0001 & 0.00 & -0.01 \\
\hline
\end{tabular}


prevention efforts in response to higher premiums. In 1996, the effect of rising prevention efforts almost completely offsets the repercussion of the reform impulse. From 1998 onward, the now decreasing premium levels let the firms cut down their prevention efforts, which leads to a slight increase of the number of accidents accompanied by an upturn of the premium growth. From the year 2000 on, the predicted growth of the ELI premium amounts to less than 0.1 per cent, and the change in the expected number of accidents per year is smaller than 0.01 . The adjustment process induced by the reform can thus be regarded as completed in that year.

How much more accidents occurred each year in the pre-reform compared to the post-reform equilibrium? From 2000 on, the year which we identified as the point where risk prevention attained its new equilibrium, the average yearly number of accidents, published on the basis of the new reporting standards, was 8.4. This corresponds with $21.9\left(=\mathrm{e}^{\log (8.4)-\zeta}\right)$ accidents in terms of old reporting standards. From Eq. (3) we can derive that the estimated number of accidents (using old reporting standards) amounted to 35.1 before the reform. The ELL thus has induced a reduction of the expected number of accidents by more than a third.

\section{Conclusion}

The ELL has partly achieved its declared objectives. It has brought a fundamental change in insurance practice while legal practice has remained largely unchanged. With the high density of insurance now reached, the internalisation effect of ELI is considerable. Its effect on accident prevention is evidently positive but works through a staggered process of interaction between insurees and insurers. This process occurs in exactly the way that the economic model proposes, that is, higher premiums and/or a greater take out of insurance policies incite firms to increase their effort to reduce environmental accidents. This result is challenging the common belief (e.g. Shavel1 ${ }^{36}$; for a more recent survey, see Baker ${ }^{37}$ ) that insurance as an "institution in the middle" is reducing the preventive incentive of liability. Based on our findings, it is the premium signal of insurers which ultimately triggers the signal of increased environmental liability to the target group of the industry and makes them move towards greater precaution. However, the path of adjustment to the post-reform equilibrium is driven by adaptive expectations on the side of the insurer. They lead to an overshooting of the insurance premium in the first years after the reform. The increased precaution of firms is taken into account in their determination with a time lag, so that it takes seven years until the information about the equilibrium premium and precaution levels is readily processed and the new equilibrium reached. This slackening intermediation between regulation and business response is supposed to create a temporary rent to the insurers.

Interestingly, this preventive effect of insurance works out even if it is decoupled from the legal underlying. Assuming that legal practices remained unchanged by the ELL so that environmental claims are difficult to make and often unsuccessful, we

\footnotetext{
${ }^{36}$ Shavell (1979).

${ }^{37}$ Baker (1996).
} 
have an interesting legal-political effect: a legal impetus which, taken by itself, has little or no real impact, but by being situated in a thriving legal and insurance context is able to shape expectations in a way that the intended effects are nevertheless achieved. Such kind of self-fulfilling prophecy is well known in the field of monetary policy ("money illusion") and can be long-lasting. ${ }^{38}$ The precondition for this effect to occur in a legal context is that the legal practice, which flows from the law, is uncertain.

\section{References}

Alberini, A. and Austin, D.H. (1999) 'Strict liability as a deterrent in toxic waste management: Empirical evidence from accident and spill data', Journal of Environmental Economics and Management 38(1): 20-48.

Alberini, A. and Austin, D.H. (2000) 'An Analysis of the Preventive Effect of Environmental LiabilityEnvironmental Liability, Location, and Emissions Substitution: Evidence from the Toxic Release Inventory', Study commissioned by DG ENV of the European Commission, Brussels, from http://ec .europa.eu/environment/legal/liability/pdf/preventive_xsum.pdf.

Alberini, A. and Austin, D.H. (2002) 'Accidents waiting to happen: Liability policy and toxic pollution releases', Review of Economics and Statistics 84(4): 729-741.

Ananthanarayanan, A. (1998) 'Is there a Green Link a Panel Data Value Event Study of the Relationship Between Capital Markets and Toxic Releases', Rutgers University, Department of Economics WP 1998-18 (1998).

Baker, T. (1996) 'On the genealogy of moral hazard', Texas Law Review 75(2): 237-292.

Bartsch, E. (1998) Liability for Environmental Damages: Incentives for Precaution and Risk Allocation, Tuebingen: Mohr Siebeck Verlag.

Blancard, G.C. and Laguna, M.A. (2006) How Do Stock Markets React to Industrial Accidents? The Case of Chemical and Oil Industry, Paper presented at the 24th Annual Meeting of the European Economic Association in Vienna.

Council Directive (2004a) Directive 2004/35/CE of the European Parliament and of the Council of 21st April 2004 on environmental liability with regand to the prevention and remedying of environmental damage. Office Journal of the European Union, 143/56.

Council Directive (2004b) Council Directive 96/82/EC of 9 December 1996 on the Control of Major-accident Hazards Involving Dangerous Substances, from http://ec.europa.eu/environment/seveso/index.htm.

Dewees, D.N. (1992) 'The comparative efficacy of tort law and regulation for environmental protection', The Geneva Papers on Risk and Insurance-Issues and Practice 17(4): 446-467.

Feess-Dörr, E., Praetorius, G. and Steger, U. (1992) Umwelthaftungsrecht, 2nd edn, Wiesbaden: GablerVerlag.

Fehr, E. and Tyran, J.R. (2001) 'Does money illusion matter?' American Economic Review 91(5): 1239-1262.

Fehr, E. and Tyran, J.R. (2006) Money Illusion and Coordination Failure, WP Nr. 1141, Munich: CESifo.

Gottwald, P. (1992) 'Die Schadenszurechnung nach dem Unwelthaftungsgesetz', in D. Medicus and H.-J. Mertens (eds.) Festschrift for Hermann Lange on his 70th Birthday, 24.1.1992, Stuttgart: Kohlhammer, pp. 447-467.

Herbst, C. (1996) Risikoregulierung durch Umwelthaftung und Versicherung, Berlin: Dunker und Humbolt.

Katzman, M.T. (1985) Chemical Catastrophes: Regulating Environmental Risk Through Pollution Liability Insurance, The Huebner Foundation, Homewood, IL: Irwin.

Kuepper, G. (1996) 'Welchen Einfluss haben Haftung und Versicherung auf die Investitionstätigkeit der Unternehmen im Umweltbereich?' Betriebs-Berater 51: 541-544.

Lanoie, P. and Laplante, B. (1994) 'The market response to environmental incidents in Canada: A theoretical and empirical analysis', Southern Economic Journal 60: 657-672.

Metzler, L.A. (1941) 'The nature and stability of inventory cycles', Review of Economic and Statistics 23(3): $113-129$.

${ }^{38}$ Fehr and Tyran $(2001,2006)$ show in a series of experiments that different effects of money illusion can cause lasting nominal price inertia. 
Muoghalu, M.I., Robison, D.H. and Glascock, J.L. (1990) 'Hazardous waste lawsuits, stockholder returns, and deterrence', Southern Economic Journal 57(2): 357-370.

Panther, S. (1992) Haftung als Instrument einer präventiven Umweltpolitik, Frankfurt/Main: Campus-Verlag.

Ringleb, A.H. and Wiggins, N.S. (1990) 'Liability and large-scale, long-term hazards', Journal of Political Economy 98(3): 574-595.

Ruetz, N. (2001) 'Versicherungsprodukte und Umwelthaftungsrecht - unter besonderer Berücksichtigung von Oeko-Audit und ISO 14001 (2001)', from www.tu-cottbus.de/btu/Fak4/.

Salje, P. (2000) 'Neuere Entwicklungen der Haftung für Gewässerschäden', Produkt- und Umwelthaftpflicht International 3: 90-97.

Schwarze, R. (1998) 'Prävention von Umweltschäden durch Umwelthaftung? Eine theoretische und empirische Analyse der Umwelthaftungsgesetzes', Jahrbuch für Wirtschaftswissenschaften 49: 198-219.

Schwarze, R. (2001) 'Environmental liability and accident prevention: Preliminary experiences in Germany', The Journal of European Environmental Policy 11(6): 314-323.

Shavell, S. (1979) 'On moral hazard and insurance', Quarterly Journal of Economics 93(4): 541-562.

Ulph, A. and Valentini, L. (2001) 'Is environmental dumping greater when plants are footloose?' Scandinavian Journal of Economics 103(4): 673-688.

Vogel, J. (1995) 'Anwendung des Umwelthaftpflicht-Modells im Breitengeschäft (Part 1)', Versicherungs wirtschaft 50: 1207-1212.

Wagner, G. (1998) 'Anmerkungen zum BGH-Urteil vom 17.6.1997', Entscheidungen zum Wirtschaftsrecht 1/ 1998: 83-86.

White, M.A. (1996) 'Investor Response to the Exxon Valdez Oil Spill, University of Virginia, McIntire School of Commerce (WHI003)', Unpublished paper, from http://etext.virginia.edu.

ZEMA (2006) 'Jahresbericht 2004', Berlin, from www.umweltbundesamt.de/zema/download.html.

\section{About the Authors}

Reimund Schwarze is Senior Researcher at the Helmholtz-Center for Environmental Research-UFZ in Leipzig and Professor for Environmental Economics at the European University Viadrina in Frankfurt/Oder.

Onno Hoffmeister is Statistical Officer at the European Statistical Office (Eurostat) in Luxemburg. He has previously held a position as Assistant Professor in Industrial Economics and Economic Policy at the University of Hamburg and has extensive experience in empirical welfare research and applied statistics. 